\title{
A phase II, randomized study of aprepitant in the prevention of chemotherapy-induced nausea and vomiting associated with moderately emetogenic chemotherapies in colorectal cancer patients
}

\author{
KUNIAKI ARIDOME $^{1,2^{*}}$, SHIN-ICHIROU MORI $^{1}$, KENJI BABA $^{1}$, MASAYUKI YANAGI $^{1}$, \\ MASAHIRO HAMANOUE ${ }^{3}$, FUTOSHI MIYAZONO ${ }^{4}$, KOUKI TOKUDA ${ }^{5}$, \\ HIROSHI IMAMURA ${ }^{6}$, YOSHITO OGURA ${ }^{7}$, KOUICHI KANEKO ${ }^{8}$, FUMIO KIJIMA $^{2}$, \\ KOUSEI MAEMURA ${ }^{1}$, SUMIYA ISHIGAMI ${ }^{1}$ and SHOJI NATSUGOE ${ }^{1}$
}

\begin{abstract}
${ }^{1}$ Department of Digestive Surgery, Breast and Thyroid Surgery, Graduate School of Medicine, Kagoshima University, Sakuragaoka, Kagoshima 890-8520; ${ }^{2}$ Department of Surgery, Saiseikai Sendai Hospital, Satsumasendai, Kagoshima 895-0074; ${ }^{3}$ Department of Surgery, Imakiire General Hospital, Kagoshima 892-8502; ${ }^{4}$ Department of Surgery, Kagoshima Prefectural Satsunan Hospital, Minamisatsuma, Kagoshima 897-1123; ${ }^{5}$ Department of Digestive Surgery, Kobayashi City Hospital, Kobayashi, Miyazaki 886-0004; ${ }^{6}$ Department of Surgery, Izumi Regional Medical Center, Akune, Kagoshima 899-1611; ${ }^{7}$ Department of Surgery, Kagoshima Kouseiren Hospital, Kagoshima 890-0061;

${ }^{8}$ Department of Surgery, Kaneko Hospital, Ichikikushikino, Kagoshima 896-0055, Japan
\end{abstract}

Received August 31,2015; Accepted December 24, 2015

DOI: $10.3892 / \mathrm{mco} .2015 .724$

\begin{abstract}
The present study aimed to study the efficacy of aprepitant in the prevention of chemotherapy-induced nausea and vomiting (CINV) in patients receiving moderately emetogenic chemotherapy (MEC) for colorectal cancer (CRC), and comprised a multicenter, phase II, open-label, randomized, parallel comparative study conducted as part of the Kagoshima aprepitant study for colon cancer in Japan. Patients with advanced or recurrent CRC were treated with standard MEC regimens (FOLFOX, XELOX or FOLFIRI) and received either standard chemotherapy [5-hydroxytryptamine-3 receptor antagonist $\left(5-\mathrm{HT}_{3} \mathrm{RA}\right)+$ dexamethasone] or aprepitant regimen chemotherapy $\left(5-\mathrm{HT}_{3} \mathrm{RA}+\right.$ reduced-dose dexamethasone + aprepitant). The primary endpoint of the present study was the proportion of patients who achieved a complete response (CR) during the overall, acute, and delayed phases of the first planned chemotherapy cycle. Secondary endpoints were complete protection, the proportions of patients without emetic episodes or nausea, patients with no more than
\end{abstract}

Correspondence to: Dr Kuniaki Aridome, Department of Surgery, Saiseikai Sendai Hospital, 2-46 Haradacho, Satsumasendai, Kagoshima 895-0074, Japan

E-mail: aridome-k3@hotmail.co.jp

Key words: chemotherapy-induced nausea and vomiting, moderately emetogenic chemotherapy, colorectal cancer, aprepitant, dexamethasone moderate nausea during the overall, acute and delayed phases, and the time to treatment failure. The CR rates in the overall, acute and delayed phases were similar in the aprepitant and the standard-regimen groups. Additionally, there were no significant differences in secondary endpoints between the two groups. In summary, aprepitant in combination with 5- $\mathrm{HT}_{3} \mathrm{RA}$ and reduced-dose corticosteroids was well tolerated and effective in preventing CINV associated with moderately emetogenic antitumor agents in Japanese patients with CRC.

\section{Introduction}

Despite considerable progress in the management of chemotherapy-induced nausea and vomiting (CINV), it remains one of the most problematic adverse effects of chemotherapy among cancer patients. Uncontrolled CINV can limit the dose intensity of chemotherapy and severely compromise a patient's quality of life (1). The occurrence of CINV depends primarily on the dose and type of chemotherapeutic agent(s) used in treatment strategies.

To the best of our knowledge, few previous studies have addressed the efficacy of anti-emetic treatment in patients receiving moderately emetogenic chemotherapy (MEC). It has been demonstrated previously that a 5-hydroxytryptamine-3 $\left(5-\mathrm{HT}_{3}\right)$ receptor antagonist (RA) plus a corticosteroid have anti-emetic effects in patients receiving MEC (2-4). The American Society of Clinical Oncology (ASCO) guidelines recommend a three-drug combination of 5- $\mathrm{HT}_{3} \mathrm{RA}$, dexamethasone and aprepitant (a neurokinin 1 RA) is administered prior to highly-emetogenic chemotherapy, however, only a two-drug combination of $5-\mathrm{HT}_{3} \mathrm{RA}$ with dexamethasone is 
recommended for MEC. Aprepitant is only added to the anti-emesis treatment for patients receiving anthracyclines and cyclophosphamide (AC) (5). The addition of aprepitant in patients receiving MEC with these agents (AC-MEC) improves the prevention of CINV $(6,7)$. According to the National Comprehensive Cancer Network guidelines, aprepitant is only recommended for patients receiving MEC regimens that include agents such as carboplatin and irinotecan. However, the characteristics of these patients are unclear, and there are no randomized trials to support this strategy for non-AC MEC. Furthermore, the Multinational Association of Supportive Care in Cancer (MASCC) does not recommend the use of aprepitant in non-AC MEC regimens (8). A phase III, gender-stratified trial in 848 patients, demonstrated that aprepitant significantly improves the primary endpoint of the study (no vomiting) as well as the secondary endpoint, complete response (CR), following MEC with AC or non-AC treatment regimens (7).

Colorectal cancer (CRC) is currently the third most common cancer worldwide (9). Approximately $20-25 \%$ of patients with the disease already have metastases at the time of diagnosis, and $50-60 \%$ of the remaining patients will go on to develop them $(10,11)$. A number of anti-cancer agents have demonstrated significant antitumor activity in metastatic CRC (mCRC), including the systemic drugs 5-fluorouracil (5-FU), irinotecan, oxaliplatin, and the oral drug capecitabine. Different combinations of these drugs, such as the FOLFOX [leucovorin (LV), 5-FU, and oxaliplatin], FOLFIRI (LV, 5-FU, and irinotecan) and XELOX regimens (oxaliplatin and capecitabine), with or without a monoclonal antibody agent, are known to improve outcomes in mCRC patients (12-15). In terms of the adjuvant chemotherapy, oxaliplatin in combination with FU, modulated by (LV) or capecitabine, is a standard therapy for non-distant mCRC patients with positive (stage III) lymph nodes (16-18). These three types of regimens are classified as non-AC MEC for CRC. The current recommended therapy for CRC patients receiving MEC is the combination of a 5-HT 3 RA and dexamethasone (19-21).

In the present study, a multicenter, open-label, randomized phase II study was conducted in order to evaluate the efficacy of aprepitant in preventing CINV following oxaliplatin- or irinotecan-based MEC (FOLFOX, XELOX or FOLFIRI) in CRC patients.

\section{Patients and methods}

Study design and patients. The present multicenter, phase II, open-label, randomized, parallel comparative study was conducted in a total of 18 institutions in Japan, as part of the Kagoshima Aprepitant Study for Colon Cancer (KASCC). The trial was conducted between September 2011 and August 2013 following approval from each institution's review board. Written, informed consent was obtained from all patients, who were enrolled using an online registration system. The patients with advanced or recurrent CRC were enrolled and stratified according to their performance status (PS; 0 or 1-2), institution, and chemotherapy regimen (FOLFOX, XELOX or FOLFIRI), and then randomly assigned to the aprepitant (5-HT $\mathrm{H}_{3} \mathrm{RA}+$ reduced-dose dexamethasone + aprepitant) or standard (5- $\mathrm{HT}_{3}+$ dexamethasone) regimen group according
Table I. Outline of the standard and aprepitant treatment regimens.

\begin{tabular}{llll}
\hline Regimen group & Day 1 & $\begin{array}{l}\text { Day 2 } \\
\text { (p.o.) }\end{array}$ & $\begin{array}{c}\text { Day 3 } \\
\text { (p.o.) }\end{array}$ \\
\hline
\end{tabular}

Standard

5-HT ${ }_{3} \mathrm{RAs}^{\mathrm{a}}$

Dexamethasone

Administered

Aprepitant

$\begin{array}{lccc}\text { 5-HT }{ }_{3} \mathrm{RAs}^{\mathrm{a}} & \text { Administered } & & \\ \text { Dexamethasone } & 6.6 \mathrm{mg} \text { i.v. } & 4 \mathrm{mg} & 4 \mathrm{mg} \\ \text { Aprepitant } & 125 \mathrm{mg} \text { p.o. } & 80 \mathrm{mg} & 80 \mathrm{mg}\end{array}$

${ }^{\mathrm{a}}$ Granisetron; $3 \mathrm{mg}$ or ondansetron; $4 \mathrm{mg}$ or azasetron; $10 \mathrm{mg}$ or palonosetron; $0.75 \mathrm{mg}$. i.v., intravenous; p.o., per os (oral).

to a computer-generated, blinded allocation schedule. The study period included the first course of chemotherapy for each patient.

Chemotherapy regimen. The following chemotherapy agents were administered intravenously (i.v.) or orally (per os; p.o.): mFOLFOX6 (LV $200 \mathrm{mg} / \mathrm{m}^{2}$ i.v. over $2 \mathrm{~h}$, prior to 5-FU day 1, 5-FU $400 \mathrm{mg} / \mathrm{m}^{2}$ i.v. bolus day 1 , followed by $2,400 \mathrm{mg} / \mathrm{m}^{2}$ i.v. over $46 \mathrm{~h}$, and oxaliplatin $85 \mathrm{mg} / \mathrm{m}^{2}$ i.v. day 1 in a 2-week cycle); XELOX (oxaliplatin $130 \mathrm{mg} / \mathrm{m}^{2}$ on day 1 , followed by oral capecitabine $1,000 \mathrm{mg} / \mathrm{m}^{2}$ twice daily on days $1-14$, in a 3-week cycle); FOLFIRI (LV $400 \mathrm{mg} / \mathrm{m}^{2}$ i.v. over $2 \mathrm{~h}$, prior to 5 -FU day 1 and 5 -FU $400 \mathrm{mg} / \mathrm{m}^{2}$ i.v. bolus day 1 , and then $2,400 \mathrm{mg} / \mathrm{m}^{2}$ i.v. over $46 \mathrm{~h}$ and irinotecan $180 \mathrm{mg} / \mathrm{m}^{2}$ i.v. over 90 min day 1 in a 2 -week cycle).

Treatment administration. Patients in the standard-regimen group received $5-\mathrm{HT}_{3} \mathrm{RA}$ and dexamethasone $9.9 \mathrm{mg}$ by i.v. on day 1 , followed by oral dexamethasone $4 \mathrm{mg}$ twice daily on days 2 and 3. Patients in the aprepitant-regimen group received oral aprepitant $125 \mathrm{mg}$ plus i.v. $5-\mathrm{HT}_{3} \mathrm{RA}$ and dexamethasone $6.6 \mathrm{mg}$ on day 1 , and oral aprepitant $80 \mathrm{mg}$ plus oral dexamethasone $2 \mathrm{mg}$ twice daily on days 2 and $3.5-\mathrm{HT}_{3} \mathrm{RAs}$ were administered by i.v. over 30-min prior to chemotherapy. Aprepitant was administered orally at $125 \mathrm{mg}$ on day 1 prior to chemotherapy, and $80 \mathrm{mg}$ each on days 2 and 3. Dexamethasone was administered by i.v. over 30-min in combination with the 5-HT 3 RA, prior to chemotherapy (Table I).

Endpoints and investigation methods. The total study period was from the initiation of chemotherapy until day 5 . The primary endpoints of the study were the proportions of patients who achieved CR (defined as no emetic episodes and no use of rescue therapy) during the overall phase (0-120 $\mathrm{h}$ post-chemotherapy), the acute phase ( $0-24 \mathrm{~h}$ post-chemotherapy), and the delayed phase (24-120 h post-chemotherapy) of the first planned chemotherapy cycle. Secondary endpoints were: i) Complete protection (CP, defined as no emesis, no rescue therapy, and no more than moderate nausea), and ii) the proportion of patients without emetic episodes or nausea, and with no more than moderate nausea during the overall, acute 


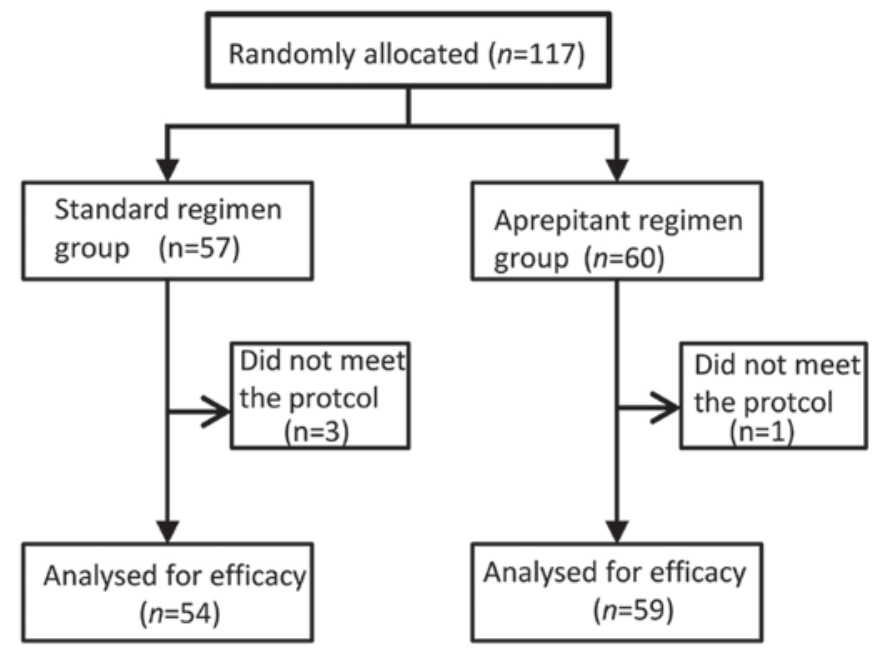

Figure 1. A flow chart of the patient inclusion/exclusion criteria.

- Standard regimen group $\quad(n=54)$

- Aprepitant regimen group $(n=59)$

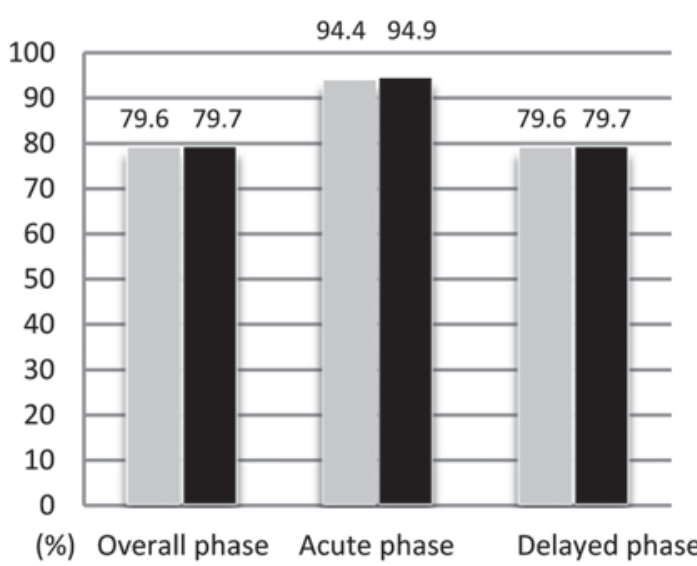

Figure 2. Complete response according to treatment phase. A bar chart of the proportion of patients that achieved a complete response (CR) in the overall, acute, and delayed phases of either the standard or aprepitant treatment regimen. CR was defined as no vomiting and no use of rescue medication. The overall, acute, and delayed phases were 0-120, 0-24, and 25-120 h, respectively, following the initiation of chemotherapy. There were no statistically significant differences between the standard or aprepitant treatment groups.

and delayed phases, and time to treatment failure (i.e., time to first emetic episode or time to administration of rescue therapy, whichever occurred first).

Patient diaries were used to record any emetic episodes, nausea, or rescue anti-emetics in daily (24 h) intervals. The presence or absence of CINV was recorded and graded according to the common terminology criteria for adverse events (CTCAE) from the National Cancer Institute, version 4.0 (available at: http://ctep.cancer.gov/protocolDevelopment/). Grade 1 or higher was considered as positive for CINV. Patients recorded the most severe nausea intensity during the previous $24 \mathrm{~h}$ period, based on a 4-point scale $(0$, none; 1 , mild; 2, moderate; 3 , severe).

Statistical analysis. The outcomes in both groups were analyzed using $\chi^{2}$ tests for primary endpoints, secondary endpoints and patients' characteristics by treatment regimen group. Two-sided two-sample t-tests were used where appropriate. $\mathrm{P}<0.05$ was considered to indicate a statistically significant difference.

\section{Results}

Patients. A total of 117 patients were randomly assigned to one of the two treatment arms (Fig. 1). Of these patients, one in the aprepitant regimen group and three in the standard regimen group were excluded from the efficacy analyses because the anti-emetic regimen was deemed to have been changed, and did not meet the inclusion protocol for the present study. Thus, in total, 113 patients were included in the full analysis set. Both treatment groups had similar baseline demographics.

The majority of patients (94.7\%) received oxaliplatin-based chemotherapy. Patient baseline characteristics, including known risk factors for CINV (female, history of alcohol use, morning sickness, motion sickness, or prior CINV), were similar between the two treatment groups (Table II).

Efficacy. The percentages of patients with CR in the overall, acute, and delayed phases for each treatment are shown in Fig. 2. The CR rates in the overall, and delayed phases were similar in the standard and aprepitant regimen groups (overall phase: $79.6 \%$ (43/54) and 79.7\% (47/59); acute phase: $94.4 \%$ (51/54) and 94.9\% (56/59); delayed phase: $79.6 \%$ (43/54) and $79.7 \%$ (47/59), respectively.

There were no significant differences between the aprepitant- and standard-regimen groups in terms of the following predefined secondary endpoints: The proportion of patients without emetic episodes, with no nausea, with no more than moderate nausea during the overall, acute and delayed phases, and the time to treatment failure (Table III and Fig. 3).

Tolerability. The adverse events reported following treatment are summarized in Table IV. The overall incidences of adverse events were similar in both groups. The incidences of leucopenia and neutropenia were similar in both treatment groups. Grade 3-4 neutropenia, defined by the National Cancer Institute toxicity criteria, occurred in 11 patients $(20.7 \%)$ in the aprepitant group and 15 patients $(25.4 \%)$ in the standard group. The neutrophil counts were similar in the two treatment groups (Table IV).

\section{Discussion}

CINV is an unpleasant adverse effect of MEC in patients with CRC, and may limit the efficacy of the treatment for this disease. The prevention and treatment of CINV are therefore important considerations for CRC patients, as well as those with other cancers. To the best of our knowledge, the present study provides the first report of a randomized trial to evaluate the efficacy of triple therapy that incudes aprepitant (with dexamethasone and a 5-HT $\mathrm{H}_{3} \mathrm{RA}$ ), for the prevention of CINV in CRC patients receiving oxaliplatin or irrinotecan-based MEC.

MEC-induced vomiting in the acute phase of treatment is known to be well-controlled by $5-\mathrm{HT}_{3}$ RA $(22,23)$. However, delayed vomiting and nausea are still poorly controlled during MEC, resulting in negative patient attitudes towards treatment 
Table II. Patient characteristics.

\begin{tabular}{|c|c|c|c|}
\hline Characteristics & Standard regimen group $(n=54)$ & Aprepitant regimen group $(n=59)$ & Comparison test \\
\hline Age, mean years $\pm \mathrm{SD}$ & $63.48 \pm 10.23$ & $66.46 \pm 9.81$ & n.s. ${ }^{\text {a }}$ \\
\hline Gender (male/female) & $30 / 24$ & $34 / 25$ & n.s. \\
\hline Smoking (no/yes) & $41 / 12$ & $44 / 15$ & n.s. \\
\hline Alcoholic drinks/week & & & \\
\hline $0 / 1 / 2-3 />4$ & $34 / 3 / 3 / 14$ & $34 / 6 / 10 / 8$ & n.s. \\
\hline $\begin{array}{l}\text { History of motion sickness } \\
\text { (no/yes) }\end{array}$ & $47 / 7$ & $49 / 10$ & n.s. \\
\hline $\begin{array}{l}\text { Chemotherapy regimen } \\
\text { (FOLFOX/FOLFIRI/XEROX) }\end{array}$ & $25 / 3 / 26$ & $19 / 3 / 37$ & n.s. \\
\hline $\begin{array}{l}\text { 5- } \mathrm{HT}_{3} \mathrm{RAs} \\
\text { Granisetron/ondansetron/ }\end{array}$ & $17 / 4 / 8 / 25$ & $13 / 2 / 7 / 37$ & n.s. \\
\hline
\end{tabular}

${ }^{\mathrm{a}} t$-test, others: $\chi^{2}$ test. SD, standard deviation; n.s., not significant.

Table III. Percentage of patients reaching efficacy endpoints by study phase and treatment group.

\begin{tabular}{|c|c|c|c|c|}
\hline \multirow[b]{2}{*}{ Endpoint } & \multicolumn{2}{|c|}{ Acute phase } & \multicolumn{2}{|c|}{ Delayed phase } \\
\hline & $\begin{array}{l}\text { Standard regimen } \\
\text { group, } \%(\mathrm{n}=54)\end{array}$ & $\begin{array}{l}\text { Aprepitant regimen } \\
\text { group, } \%(n=59)\end{array}$ & $\begin{array}{l}\text { Standard regimen } \\
\text { group, } \%(\mathrm{n}=54)\end{array}$ & $\begin{array}{l}\text { Aprepitant regimen } \\
\text { group, } \%(n=59)\end{array}$ \\
\hline Complete response & 94.4 & 94.9 & 79.6 & 79.7 \\
\hline Complete protection & 94.4 & 93.2 & 79.6 & 78.0 \\
\hline No vomiting & 94.4 & 98.3 & 81.5 & 86.4 \\
\hline No nausea & 96.3 & 89.8 & 68.5 & 64.4 \\
\hline No significant nausea ${ }^{a}$ & 100.0 & 98.3 & 88.9 & 91.3 \\
\hline
\end{tabular}

${ }^{a}$ Nausea score 0 and 1 . There were no statistically significant differences between the treatment groups for any endpoints.

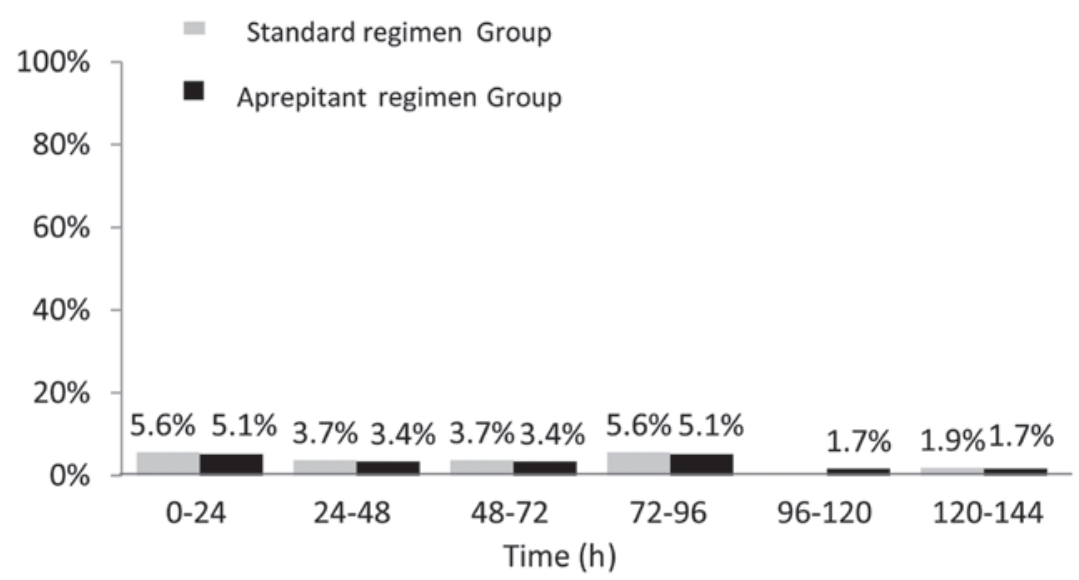

Figure 3. The time course of first vomiting or rescue episode during the first $120 \mathrm{~h}$ following chemotherapy administration. There were no statistically significant differences between the standard or aprepitant treatment groups.

and hindering the continuation of MEC. The present study investigated the addition of aprepitant to dexamethasone in the delayed phase, to determine if it could improve outcomes in
CRC patients receiving MEC. However, our results revealed there were no significant differences between the standard and aprepitant regimen in terms of complete suppression of 
Table IV. Patients with specific clinical adverse events of incidence over $5 \%$, in at least one treatment group.

\begin{tabular}{lcc}
\hline & $\begin{array}{c}\text { Standard } \\
\text { regimen group, } \\
\text { Adverse event }\end{array}$ & $\begin{array}{c}\text { Aprepitant } \\
\text { regimen group, } \\
\mathrm{n}(\%)\end{array}$ \\
\hline Anorexia & $26(48.1)$ & $26(44.1)$ \\
Fatigue & $8(14.8)$ & $6(10.2)$ \\
Diarrhea & $3(5.6)$ & $2(3.4)$ \\
Constipation & $4(7.4)$ & $1(1.7)$ \\
Oral mucositis & $3(5.6)$ & $1(1.7)$ \\
Leukopenia (grade 3-4) & $11(20.4)$ & $12(20.3)$ \\
Neutropenia (grade 3-4) & $11(20.4)$ & $15(25.4)$ \\
Thrombocytopenia & $7(13.0)$ & $4(6.8)$ \\
Total & $54(100)$ & $59(100)$ \\
\hline
\end{tabular}

No grade 3 or 4 adverse events were observed except for neutropenia and leukopenia. There were no statistically significant differences in risk of adverse events between the treatment groups.

vomiting, $\mathrm{CR}$ and $\mathrm{CP}$ rates, incidences of no vomiting and no nausea, no significant nausea, and time to treatment failure either overall, or in the acute or delayed phase. Similarly, there were no notable differences in adverse events between the standard and aprepitant regimens.

The MASCC (24) and ASCO guidelines (25) recommend palonosetron as the preferred 5- $\mathrm{HT}_{3} \mathrm{RA}$ for non-AC MEC regimens, and thus, the use of palonosetron instead of granisetron may improve delayed CINV in this setting. Moreover, a recent study from the Rochester Cancer Center demonstrated that delayed nausea was significantly improved by the administration of additional dexamethasone on days 2 and 3; however, there was no difference between palonosetron and granisetron during highly-emetogenic chemotherapy or MEC (26). The difference between palonosetron and granisetron would be expected to be small. As noted previously, the suggested optimum dose of dexamethasone for standard prophylaxis is $20 \mathrm{mg}$ in combination with a $5-\mathrm{HT}_{3} \mathrm{RA}(27)$.

The addition of dexamethasone to $5-\mathrm{HT}_{3} \mathrm{RA}$ has been reported to improve total control rates by $9.8-13.4 \%$ at $24 \mathrm{~h}$, and by $4.7-8.7 \%$ at $48 \mathrm{~h}(22,28)$. However, while corticosteroids (dexamethasone) are recommended for treating delayed nausea and vomiting, their side effects remain a concern for many clinical oncologists (29). In the present study, the dexamethasone dose was $9.9 \mathrm{mg}$ on day 1 , and $8 \mathrm{mg}$ p.o. on days 2 and 3 . Aprepitant is a substrate and inhibitor of CYP3A4, known to increase plasma dexamethasone concentrations (30). Therefore, to achieve comparable plasma levels of dexamethasone in the presence of aprepitant, the dose of dexamethasone was $6.6 \mathrm{mg}$ i.v. on day 1 and $4 \mathrm{mg}$ p.o. on days 2 and 3 in the aprepitant regimen. Both the i.v. and p.o. doses of dexamethasone could therefore be reduced when combined with aprepitant, in comparison to the standard regimen for MEC. The lower dose of dexamethasone in the aprepitant regimen may therefore help to reduce the side effects associated with long-term corticosteroids administration during MEC in patients with CRC, and may therefore also help to maintain the quality of life in these patients.
In conclusion, the present study demonstrates that aprepitant in combination with a 5- $\mathrm{HT}_{3} \mathrm{RA}$ and reduced dose of corticosteroid was well tolerated and effective for preventing CINV associated with MEC in Japanese patients with CRC.

\section{References}

1. Oo TH and Hesketh PJ: Drug insight: New anti-emetics in the management of chemotherapy-induced nausea and vomiting. Nat Clin Pract Oncol 2: 196-201,2005.

2. Soukop M, McQuade B, Hunter E, Stewart A, Kaye S, Cassidy J, Kerr D, Khanna S, Smyth J and Coleman R: Ondansetron compared with metoclopramide in the control of emesis and quality of life during repeated chemotherapy for breast cancer. Oncology 49: 295-304, 1992.

3. Sigsgaard T, Herrstedt J, Andersen LJ, Havsteen H, Langer SW, Kjaerbøl AG, Lund H, Kjaer M and Dombernowsky P: Granisetron compared with predonisolone plus metopimazine as anti-emetic prophylaxis during multiple cycles of moderately emetogenic chemotherapy. Br J Cancer 80: 412-418, 1999.

4. Sigsgaard T, Herrstedt J, Handberg J, Kjaer M and Dombernowsky P: Ondansetron plus metopimazine compared with ondansetron plus metopimazine plus prednisolone as anti-emetic prophylaxis in patients receiving multiple cycles of moderately emetogenic chemotherapy. J Clin Oncol 19: 2091-2097, 2001.

5. American Society of Clinical Oncology; Kris MG, Hesketh PJ, Somerfield MR, Feyer P, Clark-Snow R, Koeller JM, Morrow GR, Chinnery LW, Chesney MJ, Gralla RJ and Grunberg SM: American society of clinical oncology guideline for anti-emetics in oncology: Update 2006. J Clin Oncol 24: 2932-2947, 2006.

6. Warr DG, Hesketh PJ, Gralla RJ, Muss HB, Herrstedt J, Eisenberg PD, Raftopoulos H, Grunberg SM, Gabriel M, Rodgers A, et al: Efficacy and tolerability of aprepitant for the prevention of chemotherapy-induced nausea and vomiting in patients with breast cancer after moderately emetogenic chemotherapy. J Clin Oncol 23: 2822-2830, 2005.

7. Rapoport BL, Jordan K, Boice JA, Taylor A, Brown C, Hardwick JS, Carides A, Webb T and Schmoll HJ: Aprepitant for the prevention of chemotherapy-induced nausea and vomiting associated with a broad range of moderately emetogenic chemotherapies and tumor types: A randomized, double-blind study. Support Care Cancer 18: 423-431, 2010.

8. Roila F, Warr D, Aapro M, Clark-Snow RA, Einhorn L, Gralla RJ, Herrstedt J, Saito M and Tonato M: Delayed emesis: Moderately emetogenic chemotherapy (single-day chemotherapy regimens only). Support Care Cancer 19 (Suppl 1): S57-S62, 2011.

9. Ferlay J, Shin HR, Bray F, Forman D, Mathers C and Parkin DM: Estimates of worldwide burden of cancer in 2008: GLOBOCAN 2008. Int J Cancer 127: 2893-2917, 2010.

10. Van Cutsem E and Oliveira J; ESMO Guidelines Working Group: Advanced colorectal cancer: ESMO clinical recommendations for diagnosis, treatment and follow-up. Ann Oncol 20 (Suppl 4): S61-S63, 2009.

11. Yoo PS, Lopez-Soler RI, Longo WE and Cha CH: Liver resection for metastatic colorectal cancer in the age of neoadjuvant chemotherapy and bevacizumab. Clin Colorectal Cancer 6: 202-207, 2006.

12. de Gramont A, Figer A, Seymour M, Homerin M, Hmissi A, Cassidy J, Boni C, Cortes-Funes H, Cervantes A, Freyer G, et al: Leucovorin and fluorouracil with or without oxaliplatin as first-line treatment in advanced colorectal cancer. J Clin Oncol 18: 2938-2947, 2000.

13. Hurwitz H, Fehrenbacher L, Novotny W, Cartwright T, Hainsworth J, Heim W, Berlin J, Baron A, Griffing S, Holmgren E, et al: Bevacizumab plus irinotecan, fluorouracil, and leucovorin for metastatic colorectal cancer. N Engl J Med 350: 2335-2342, 2004.

14. Saltz LB, Clarke S, Díaz-Rubio E, Scheithauer W, Figer A, Wong R, Koski S, Lichinitser M, Yang TS, Rivera F, et al: Bevacizumab in combination with oxaliplatin-based chemotherapy as first-line therapy in metastatic colorectal cancer: A randomized phase III study. J Clin Oncol 26: 2013-2019, 2008.

15. Cassidy J, Tabernero J, Twelves C, Brunet R, Butts C, Conroy T, Debraud F, Figer A, Grossmann J, Sawada N, et al: XELOX (capecitabine plus oxaliplatin): Active first-line therapy for patients with metastatic colorectal cancer. J Clin Oncol 22: 2084-2091, 2004

16. André T, Boni C, Mounedji-Boudiaf L, Navarro M, Tabernero J, Hickish T, Topham C, Zaninelli M, Clingan P, Bridgewater J, et al: Oxaliplatin, fluorouracil, and leucovorin as adjuvant treatment for colon cancer. N Engl J Med 350: 2343-2351, 2004. 
17. André T, Boni C, Navarro M, Tabernero J, Hickish T, Topham C, Bonetti A, Clingan P, Bridgewater J, Rivera F and de Gramont A: Improved overall survival with oxaliplatin, fluorouracil, and leucovorin as adjuvant treatment in stage II or III colon cancer in the MOSAIC trial. J Clin Oncol 27: 3109-3116, 2009.

18. Haller DG, Tabernero J, Maroun J, de Braud F, Price T, Van Cutsem E, Hill M, Gilberg F, Rittweger K and Schmoll HJ: Capecitabine plus oxaliplatin compared with fluorouracil and folinic acid as adjuvant therapy for stage III colon cancer. J Clin Oncol 29: 1465-1471, 2011.

19. Prevention of chemotherapy- and radiotherapy-induced emesis: Results of the perugia consensus conference. Antiemetic subcommittee of the multinational association of supportive care in cancer (MASCC). Ann Oncol 9: 811-819, 1998.

20. Gralla RJ, Osoba D, Kris MG, Kirkbride P, Hesketh PJ, Chinnery LW, Clark-Snow R, Gill DP, Groshen S, Grunberg S, et al: Recommendations for the use of anti-emetics: Evidence-based, clinical practice guidelines. American society of clinical oncology. J Clin Oncol 17: 2971-2994, 1999.

21. Herrstedt J, Aapro MS, Roila F and Kataja VV; ESMO, Guidelines Task Force: ESMO minimum clinical recommendations for prophylaxis of chemotherapy-induced nausea and vomiting (NV). Ann Oncol 16 (Suppl 1): i77-i79, 2005.

22. Perez EA, Hesketh P, Sandbach J, Reeves J, Chawla S, Markman M, Hainsworth J, Bushnell W and Friedman C: Comparison of single-dose oral granisetron versus intravenous ondansetron in the prevention of nausea and vomiting induced by moderately emetogenic chemotherapy: A multicenter, double-blind, randomized parallel study. J Clin Oncol 16 : 754-760, 1998.

23. Jordan K, Hinke A, Grothey A, Voigt W, Arnold D, Wolf HH and Schmoll HJ: A meta-analysis comparing the efficacy of four $5-\mathrm{HT}_{3}$-receptor antagonists for acute chemotherapy-induced emesis. Support Care Cancer 15: 1023-1033, 2007.
24. Roila F, Herrstedt J, Aapro M, Gralla RJ, Einhorn LH, Ballatori E, Bria E, Clark-Snow RA, Espersen BT, Feyer P, et al: Guideline update for MASCC and ESMO in the prevention of chemotherapy- and radiotherapy-induced nausea and vomiting: Results of the Perugia consensus conference. Ann Oncol 21 (Suppl 5): v232-v243, 2010

25. Basch E, Prestrud AA, Hesketh PJ, Kris MG, Feyer PC, Somerfield MR, Chesney M, et al: Antiemetics: American society of clinical oncology clinical practice guideline update. J Clin Oncol 29: 4189-4198, 2011.

26. Roscoe JA, Heckler CE, Morrow GR, Mohile SG, Dakhil SR, Wade JL and Kuebler JP: Prevention of delayed nausea: A University of Rochester cancer center community clinical oncology program study of patients receiving chemotherapy. J Clin Oncol 30: 3389-3395, 2012.

27. Double-blind, dose-finding study of four intravenous doses of dexamethasone in the prevention of cisplatin-induced acute emesis. Italian group for anti-emetic research. J Clin Oncol 16: 2937-2942, 1998

28. Gralla RJ, Navari RM, Hesketh PJ, Popovic W, Strupp J, Noy J, Einhorn L, Ettinger D, Bushnell W and Friedman C: Single-dose oral granisetron has equivalent anti-emetic efficacy to intravenous ondansetron for highly emetogenic cisplatin-based chemotherapy. J Clin Oncol 16: 1568-1573, 1998.

29. Vardy J, Chiew KS, Galica J, Pond GR and Tannock IF: Side effects associated with the use of dexamethasone for prophylaxis of delayed emesis after moderately emetogenic chemotherapy. $\mathrm{Br}$ J Cancer 94: 1011-1015, 2006.

30. Hesketh PJ, Grunberg SM, Gralla RJ, Warr DG, Roila F, de Wit R, Chawla SP, Carides AD, Ianus J, Elmer ME, et al: The oral neurokinin-l antagonist aprepitant for the prevention of chemotherapy-induced nausea and vomiting: A multinational, randomized, double-blind, placebo-controlled trial in patients receiving high-dose cisplatin-the aprepitant protocol 052 study group. J Clin Oncol 21: 4112-4119, 2003. 